\title{
Developmental changes in mesenteric artery reactivity in embryonic and newly hatched chicks
}

\author{
Rob M. Moonen • Eduardo Villamor
}

Received: 26 January 2011/Revised: 10 May 2011 / Accepted: 13 May 2011/Published online: 28 May 2011

(C) The Author(s) 2011. This article is published with open access at Springerlink.com

\begin{abstract}
At birth, the intestine becomes the sole site for nutrient absorption requiring a dramatic increase in blood flow. The vascular changes accompanying this transition have been partly characterized in mammals. We investigated, using wire myography, the developmental changes in chick mesenteric artery (MA) reactivity. Rings of the MA from 15-day (E15) and 19-day (E19) chicken embryos (total incubation 21 days) as well as non-fed 0-3-h-old (NH3h) and first-fed 1-day-old (NH1d) newly hatched chicks contracted in response to $\mathrm{KCl}$, norepinephrine (NE), U46619, and endothelin (ET)-1 and relaxed in response to acetylcholine (ACh), sodium nitroprusside (SNP), and forskolin indicating the presence of electro- and pharmacomechanical coupling as well as cGMP- and cAMP-mediated relaxation. In ovo development and transition to ex ovo life was accompanied by alterations in the response of the MAs, but a different developmental trajectory was observed for each reactivity pathway tested. Thus, the contractile efficacy of $\mathrm{KCl}$ underwent a linear increase $(\mathrm{E} 15<\mathrm{E} 19<\mathrm{NH} 3 \mathrm{~h}<\mathrm{NH} 1 \mathrm{~d})$. The efficacy of $\mathrm{NE}$ and U46619 increased in ovo, but not ex ovo $(\mathrm{E} 15<$ $\mathrm{E} 19=\mathrm{NH} 3 \mathrm{~h}=\mathrm{NH} 1 \mathrm{~d})$ and the efficacy of ET-1 peaked at $\mathrm{E} 19(\mathrm{E} 15<\mathrm{E} 19>\mathrm{NH} 3 \mathrm{~h}=\mathrm{NH} 1 \mathrm{~d})$. The relaxations
\end{abstract}

Communicated by H.V. Carey.

\section{R. M. Moonen}

Department of Pediatrics, Atrium Medical Centre Parkstad, Heerlen, The Netherlands

R. M. Moonen · E. Villamor $(\varangle)$

Department of Pediatrics, Maastricht University Medical Center (MUMC+), Research Institute Growth and Development (GROW), University of Maastricht, P.O. Box 5800,

P. Debyelaan 25, 6202 AZ Maastricht, The Netherlands

e-mail: e.villamor@mumc.nl elicited by ACh (endothelium-dependent), SNP, and forskolin did not undergo significant developmental changes. In conclusion, the ability of chick MAs to constrict in response to pharmacological stimuli increases during the embryonic period, but no dramatic changes are induced by hatching or the first feeding. Maturation of vasodilator mechanisms precedes that of vasoconstrictor mechanisms. Alterations of the delicate balance between vasoconstrictors and vasodilators may play an important role in perinatal intestinal diseases.

Keywords Mesenteric artery - Chicken embryo · Vascular reactivity

\section{Introduction}

The placenta is the organ responsible for nutrition of the mammalian fetus. Consequently, the fetal intestine is a relatively dormant organ which presents a low-flow, high-resistance vascular bed that is adequate to meet its limited tissue $\mathrm{O}_{2}$ demand (Edelstone and Holzman 1982; Nankervis et al. 2001; Reber et al. 2002). After birth, the intestine becomes the sole site for nutrient absorption and the rate of intestinal growth increases, requiring a dramatic increase in blood flow. The intestinal vascular changes that accompany the transition between the fetal and the neonatal life have been characterized in several mammalian species, including pig and sheep (Edelstone and Holzman 1982; Heymann et al. 1981; Nankervis et al. 2001; Reber et al. 2002).

The most pressing reason to study the fetal and neonatal intestinal circulation is to clarify its putative role in the pathogenesis of necrotizing enterocolitis (NEC) (Nankervis et al. 2008). NEC is the most common life-threatening 
gastrointestinal emergency encountered in the neonatal intensive care unit. The pathophysiology of NEC remains elusive and is likely multifactorial (Moonen et al. 2007, 2010a; Nankervis et al. 2008; Wolfs et al. 2009). Recently, it has been proposed that a misbalance between vasoconstriction and vasodilatation in the immature intestine may predispose to NEC (Lin et al. 2008; Nankervis et al. 2008). However, only a limited number of observations have been made on the development of fetal intestinal circulation in mammals (Edelstone and Holzman 1982; Wolfs et al. 2009) because mammalian models are technically complex and experimental manipulations affect both the mother and the fetus (Ruijtenbeek et al. 2002; Sutendra and Michelakis 2007). Therefore, there is a need for additional models, addressing these limitations (Ruijtenbeek et al. 2002; Sutendra and Michelakis 2007).

In the last few years, the chicken embryo has emerged as a suitable model for studying developmental vascular biology (Agren et al. 2007, 2008, 2009; Moonen et al. 2010b; Rouwet et al. 2000; Ruijtenbeek et al. 2002; Sutendra and Michelakis 2007; Villamor et al. 2002; Zoer et al. 2009, Zoer et al. 2010a, b). In contrast to mammals, which depend on a continuous transference of nutrients from the maternal circulation to the developing fetus, all the nutrients required for the formation and growth of the chicken embryo are pre-packaged in the egg at the time of laying (Speake et al. 1998). Glucose and aminoacids form the main energy source during the first stages of chicken embryo development, but latter, the lipids of the yolk represent the primary nutrient source, providing over $90 \%$ of the energy required (Powell et al. 2004; Speake et al. 1998). Yolk lipids and other constituents are transferred to the embryonic circulation through the yolk sac membrane, a highly vascularised structure that grows outward from the embryo to envelope the whole of the yolk (Speake et al. 1998). Towards the end of incubation, the remaining yolk is internalized into the abdominal cavity and provides nutrient reserves for several days (Noy and Sklan 2001; Sklan 2003). In the hatching chick, yolk is utilized simultaneously via two routes. One route is by phagocytosis or endocytosis of yolk contents to the circulation, while the other is by transport through the yolk stalk into the small intestine (Sklan 2003). However, chicks are precocial and directly forage for exogenous feed (Uni et al. 2003). Therefore, the immediate posthatch period is characterized by a transition from the use of lipid-rich yolk as the nutrient source to exogenous feed rich in carbohydrates and proteins (Noy and Sklan 1998, 2001; Sklan 2003). This transition is accompanied by rapid physical and functional development of the gastrointestinal tract (Biviano et al. 1993; Uni et al. 2003), but its effects on the intestinal circulation have not been studied so far.
In a previous study, Rouwet et al. (2000) characterized, using intravital microscopy, the vasomotor responses of mesenteric arteries from 13 to 17-day-old chicken embryos (total incubation time 21 days). They observed that acetylcholine (ACh)-induced relaxation and norepinephrine (NE)- and hypoxia-induced contraction were already present at these developmental stages. The ability of mesenteric arteries to constrict increased with development, whereas vasodilator responses remained unchanged (Rouwet et al. 2000). Thus, the study of Rouwet et al. demonstrated the presence of pharmacomechanical coupling in the chicken embryo mesenteric vasculature but, unfortunately, they did not examine a larger number of vasoactive agonists and only compared two relative immature vessels without analyzing further maturation. In the present study, we hypothesized that the chicken mesenteric vascular reactivity undergoes further developmental changes during transition to ex ovo life and, more particularly, after the first feed. To test our hypothesis, we analyzed the response of mesenteric arteries from chicken embryos (15 and 19 days) and hatchlings ( $<3$-h-old and 1-day-old) to constrictor and relaxant agonists.

\section{Methods}

Incubation of chicken (Gallus gallus) embryos and vessel isolation

All experimental procedures were carried out in accordance with the Dutch Law on Animal Experimentation and the European Directive for the Protection of Vertebrate Animals Used for Experimental and Other Scientific Purposes (86/609/EU) and approved by the Committee on Animal Experimentation of the University of Maastricht. Fertilized eggs from White Leghorn chickens (t Anker, Ochten, The Netherlands) were incubated at $37.8^{\circ} \mathrm{C}, 45 \%$ humidity and rotated once per hour over an angle of $90^{\circ}$ (Incubator model 25HS, Masalles Comercial, Spain). At day 15 (E15) or 19 (E19) of the 21 days of incubation, some embryos were used for experiments and others allowed to hatch. Hatchlings were used within the first $3 \mathrm{~h}$ (NH3h) or transferred to a brooder unit under $23 \mathrm{~h}$ /day of continuous light and temperature of $35^{\circ} \mathrm{C}$ and provided ad libitum access to water and a standard starter diet (Zoer et al. 2009). This last group of chicks was studied within the second day post-hatch (NH1d).

On the experimental day, the animals were killed by decapitation, placed on the dorsal side on a Petri-dish coated with silicon and a midline laparotomy and sternotomy were performed. With the aid of a dissecting microscope, the cranial MA was carefully dissected free from surrounding tissue. The cranial MA is the vessel that supplies most of 
chicken intestine and also the yolk sac during the embryonic period (Levinsohn et al. 1984). Only the intestinal part of the artery (i.e. the part distal to the emergence of the branch which supplies the yolk sac) was used in our study.

\section{Recording of arterial reactivity}

Two stainless steel wires (diameter $40 \mu \mathrm{m}$ ) were inserted into the lumen of the vessels, which were mounted as a 1.7-2-mm length ring segment between an isometric force transducer and a displacement device in a myograph (Danish Myo Technology A/S model $610 \mathrm{M}$, Aarhus, Denmark). The segment lengths were determined with the aid of an eyepiece scale which was incorporated in the dissecting microscope. The myograph organ bath $(5 \mathrm{~mL}$ vol) was filled with Krebs-Ringer bicarbonate (KRB, composition in $\mathrm{mmol} \mathrm{L}^{-1}$ : $\mathrm{NaCl}, 118.5 ; \mathrm{KCl}, 4.75$; $\mathrm{MgSO}_{4} \cdot 7 \mathrm{H}_{2} \mathrm{O}, 1.2 ; \mathrm{KH}_{2} \mathrm{PO}_{4}, 1.2 ; \mathrm{NaHCO}_{3}, 25.0 ; \mathrm{CaCl}_{2}$, 2.5; glucose, 5.5) buffer maintained at $39^{\circ} \mathrm{C}$ and aerated with $95 \% \mathrm{O}_{2} / 5 \% \mathrm{CO}_{2}\left(\mathrm{PO}_{2} 82.3 \mathrm{kPa}, \mathrm{SD} 6.9, n=12\right.$, measured with an ABL 510 blood gas analyzer, Radiometer Copenhagen, Denmark). After an equilibration period of $30 \mathrm{~min}$, the vessels were distended to their individual optimal diameter, which evoked a resting tension corresponding to a transmural pressure of 10 (E15) or $20 \mathrm{mmHg}$ (E19 and hatchlings). These pressures correspond to the mean arterial blood pressure reported in chicken at the corresponding age (Altimiras and Crossley 2000) and elicited the highest contractile response to $\mathrm{KCl}$, as determined in pilot experiments. After $30 \mathrm{~min}$ of incubation under resting tension, a control reference contraction was elicited by raising the $\mathrm{K}^{+}$concentration of the buffer $(62.5 \mathrm{mM})$ in exchange for $\mathrm{Na}^{+}$.

\section{Contractile responses}

Concentration-response curves to $\mathrm{KCl}(31.25-125 \mathrm{mM})$, the nonselective adrenergic receptor agonist NE (10 nM$0.1 \mathrm{mM}$ ), the thromboxane/prostaglandin $\mathrm{H}_{2}(\mathrm{TP})$ receptor agonist U-46619 (10 nM-3 $\mu \mathrm{M})$, and endothelin (ET)-1 $(0.1 \mathrm{nM}-0.1 \mu \mathrm{M})$ were constructed by increasing the organ chamber concentration of the drug, by cumulative increments after a steady state response had been reached with each increment. When two or more agonists were studied in the same arterial preparation, the vessels were repeatedly washed and allowed to equilibrate for at least $30 \mathrm{~min}$. If the tone did not recover to resting level, the vessels were discarded for further experiments.

\section{Relaxant responses}

Concentration-response curves to relaxants were constructed following establishment of stable contraction with
$\mathrm{NE}(10 \mu \mathrm{M})$ or $\mathrm{KCl}(62.5 \mathrm{mM})$. The muscarinic receptor agonist acetylcholine (ACh, $10 \mathrm{nM}-0.1 \mathrm{mM}$ ), the nitric oxide (NO) donor sodium nitroprusside (SNP, $10 \mathrm{nM}-$ $0.1 \mathrm{mM}$ ) and the adenylate cyclase activator forskolin $(10 \mathrm{nM}-10 \mu \mathrm{M})$ were studied. Some experiments were performed in endothelium-denuded vessels. The endothelium was removed by gentle rubbing of the vessel lumen with a horse tail hair and its effective removal was verified in pilot experiments by scanning electron microscopy, as previously described (Agren et al. 2008; Lindgren et al. 2010). Other experiments were performed in the presence of the NO synthase inhibitor N $\omega$-nitro-L-arginine methyl ester (L-NAME, $0.1 \mathrm{mM}$ ), or the soluble guanylate cyclase (sGC) inhibitor $1 \mathrm{H}[1,2,4]$ oxadiazolo[4,3-a]quinoxalin-1one (ODQ, $10 \mu \mathrm{M})$.

\section{Drugs and solutions}

Solutions containing different concentrations of $\mathrm{K}^{+}$were prepared by replacing part of the $\mathrm{NaCl}$ of the KRB buffer by an equimolar amount of $\mathrm{KCl}$. Arterenol bitartrate (NE), ACh, SNP, L-NAME, L-arginine and forskolin were obtained from Sigma (St. Louis, MO); U-46619 was from Cayman Chemical (Ann Arbor, MI), and ODQ was from Tocris (Ballwin, MO). All drugs were dissolved initially in distilled deionized water (except U46619 and ODQ in DMSO and forskolin in ethanol) to prepare adequate stock solutions and further dilutions were also made in deionized water. The final bath concentration of DMSO or ethanol did not exceed $0.1 \%$ and had no effect on mechanical activity.

\section{Data analysis}

The results are shown as mean (SD) of measurements in $n$ animals. For clarity, the results are shown in the figures as mean \pm SEM. Contractions are expressed in terms of active wall tension $(\mathrm{mN} / \mathrm{mm}$, calculated as the force divided by twice the length of the segment) or as a percentage of the reference contraction to $\mathrm{KCl}(62.5 \mathrm{mM})$ performed for each individual ring at the beginning of the experiment. The relaxant responses are expressed as the percentage of reduction in the contraction induced by $\mathrm{NE}$ or $\mathrm{KCl}$. Sensitivity/potency (expressed as $p D_{2}=-\log \mathrm{EC}_{50}$ ) and efficacy (expressed as $E_{\max }$ ) were calculated by nonlinear regression analysis of the concentration-response curves. In the case of several contractile agonists, a maximal effect was not reached, not allowing the calculation of the $p D_{2}$. Thus, the $\mathrm{ED}_{20}$ (concentration of agonist causing a contraction representing $20 \%$ of the reference contraction to $62.5 \mathrm{mM} \mathrm{KCl}$ ) was calculated using nonlinear regression (Gluais et al. 2005). The $-\log \mathrm{ED}_{20}$ was used to express the potency of NE, ET-1 and U46619. Differences between 
mean values were assessed by one-way ANOVA followed by Bonferroni's post hoc $t$ test. Differences were considered significant at a $P<0.05$. All analyses were performed using GraphPad Prism (version 5.00 for Windows, GraphPad Software, San Diego California USA, http://www.graphpad.com).

\section{Results}

The mean body mass of the animals was E15:12.99 $\mathrm{g}$ (SD 0.93, $n=40, P<0.001$ vs. the other ages), E19: $27.97 \mathrm{~g}$ (SD 2.85, $n=47, P<0.001$ vs. NH3h and NH1d); NH3h: $41.82 \mathrm{~g}$ (SD 3.16, $n=50$ ); and NH1d: $40.25 \mathrm{~g}$ (SD 2.92, $n=16$ ). The mean optimal diameter of the MA rings did not significantly change with age (E15: $716 \mu \mathrm{m}, \mathrm{SD} 105$, $n=40$; E19: $702 \mu \mathrm{m}, \mathrm{SD} 117, n=47$; NH3h:707 $\mu \mathrm{m}, \mathrm{SD}$ 94, $n=50$; NH1d: $653 \mu \mathrm{m}$, SD 73, $n=16$ ).

Contractile responses

$\mathrm{KCl}$ (31.25-125 mM, Fig. 1), NE (10 nM-0.1 mM, Fig. 2), ET-1 (0.1 nM-0.1 $\mu \mathrm{M}$, Fig. 3a-c) and U46619 $(10 \mathrm{nM}-3 \mu \mathrm{M}$, Fig. $3 \mathrm{~d}$, e) contracted the MA rings in a concentration-dependent manner. As shown in Fig. 1b, the contractile efficacy $\left(E_{\max }\right)$ of $\mathrm{KCl}$ underwent a linear increase $(\mathrm{E} 15<\mathrm{E} 19<\mathrm{NH} 3 \mathrm{~h}<\mathrm{NH} 1 \mathrm{~d})$, whereas the potency $\left(p D_{2}\right)$ did not change (Fig. 1c). The efficacy of NE (Fig. 2b) and U46619 (Fig. 3d) increased in ovo, but not ex ovo $($ E15 $<$ E19 $=$ NH3h $=$ NH1d $)$. The potency $(-\log$
$\mathrm{ED}_{20}$ ) of NE peaked in the NH3h and decreased at NH1d (Fig. 2c), whereas the contractile potency of U46619 (Fig. 3e) was not significantly different in the four groups of age. The efficacy of ET-1 (Fig. 3b) peaked at E19 $(\mathrm{E} 15<\mathrm{E} 19>\mathrm{NH} 3 \mathrm{~h}=\mathrm{NH} 1 \mathrm{~d})$ and the potency decreased with age (Fig. 3c). As shown in Fig. 3a, high concentrations of ET-1 $(0.1 \mu \mathrm{M})$ evoked a relaxant response in the rings from NH chicks. This relaxant effect of ET-1 was not observed at E15 or E19 (Fig. 3a).

\section{Relaxant responses}

As shown in Fig. 4, the muscarinic receptor agonist $\mathrm{ACh}$ $(10 \mathrm{nM}-0.1 \mathrm{mM})$, the NO donor SNP $(10 \mathrm{nM}-0.1 \mathrm{mM})$ and the adenylate cyclase activator forskolin $(10 \mathrm{nM}-$ $10 \mu \mathrm{M})$ relaxed NE- and $\mathrm{KCl}$-contracted MA rings in a concentration-dependent manner. The response to $\mathrm{ACh}$ was abolished by mechanical removal of the endothelium, whereas SNP- and forskolin-induced relaxations were not affected by this (data not shown). The relaxant efficacies $\left(E_{\max }\right)$ of ACh (Fig. 4b) and SNP (Fig. 4d) were significantly impaired in $\mathrm{KCl}$-contracted MAs when compared with NE-contracted vessels. This effect of $\mathrm{KCl}$ contraction on relaxant efficacy was not observed for forskolin (with the exception of E15 MAs, Fig. 4f).

The relaxant efficacy of ACh did not change with age (Fig. 4b), but the potency was significantly lower in the E15 (Fig. 4c). As shown in Fig. 4b, the relaxant efficacy of ACh was impaired by the presence of the NO synthase inhibitor L-NAME. However, this effect of L-NAME was
A

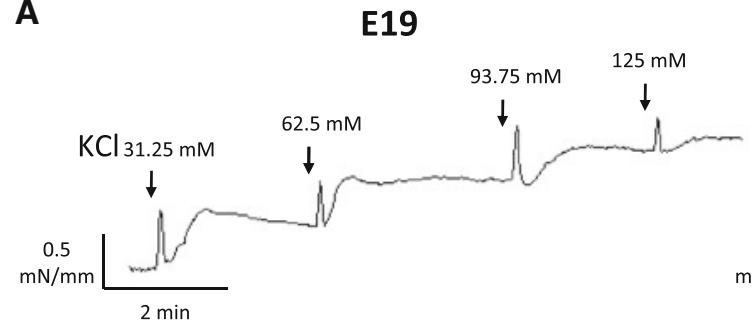

B

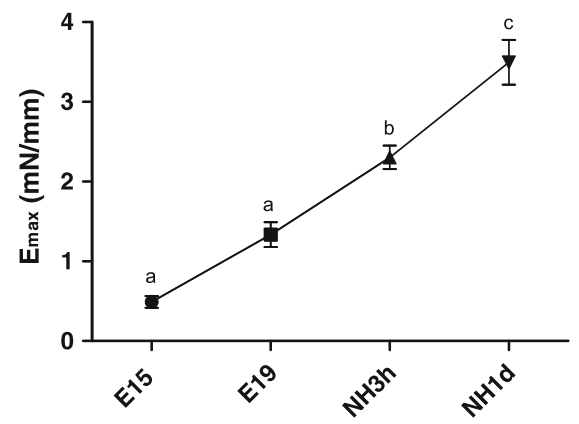

Fig. 1 Contractile effects of $\mathrm{KCl}$ in mesenteric arteries from 15-day (E15) and 19-day (E19) chicken embryos and 3-h-old (NH3 h) and 1-day-old (NH1d) newly hatched chicks. Values (mean \pm SEM)

\section{NH1d}
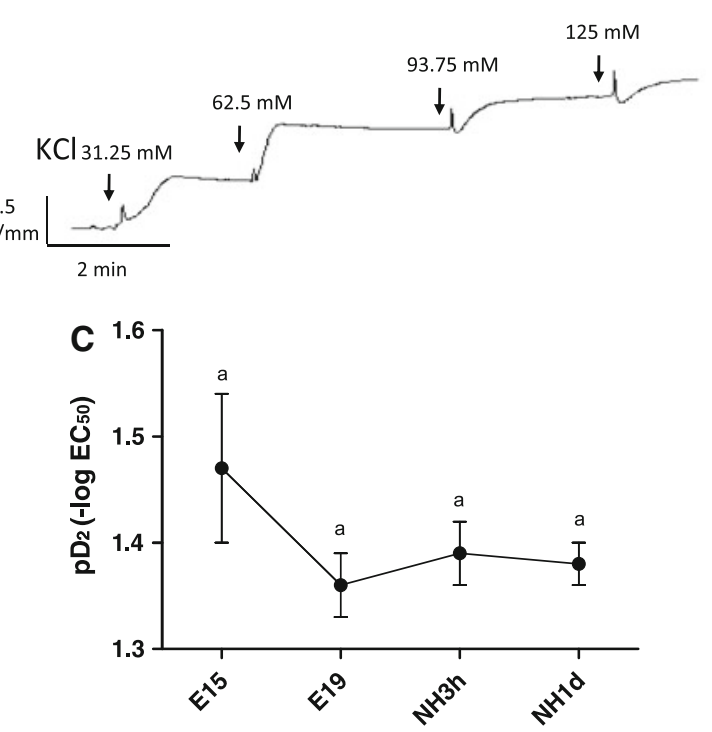

without a common letter are significantly different $(P<0.05)$. In a (representative tracings), numbers above the arrows indicate $[\mathrm{KCl}]$ 
A

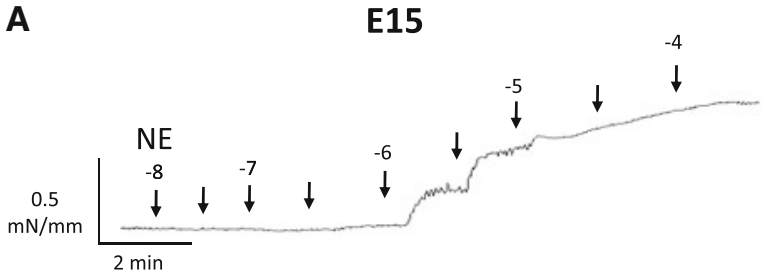

B

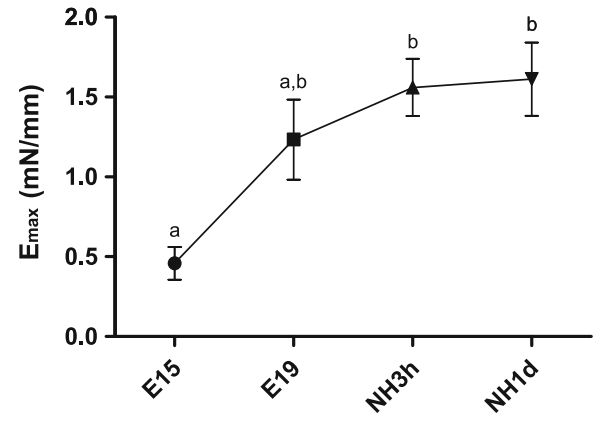

Fig. 2 Contractile effects of norepinephrine (NE) in mesenteric arteries from 15-day (E15) and 19-day (E19) chicken embryos and 3-h-old (NH3h) and 1-day-old (NH1d) newly hatched chicks. Values (mean $\pm \mathrm{SEM}$ ) without a common letter are significantly different

only observed in the embryonic arteries (E15 and E19). On the other hand, L-NAME decreased the potency of ACh in the E15 and the NH1d arteries, but not in the E19 or NH3h vessels (Fig. 4c).

The relaxant efficacy (Fig. 4d) and potency (Fig. 4e) of SNP underwent a slight, but significant decrease with age. Both SNP potency and efficacy were significantly impaired by the presence of the guanylate cyclase inhibitor ODQ. Finally, the relaxant efficacy of forskolin did not change with age (Fig. 4f), but the potency peaked in the NH3h arteries and significantly decreased afterwards (E15 = E19 $<$ NH3h $>$ NH1d, Fig. 4g).

\section{Discussion}

During prenatal life, endothelial and vascular smooth muscle cells play a key role in blood vessel morphogenesis and exhibit high rates of proliferation, migration, and production of extracellular matrix (Owens et al. 2004; Rzucidlo et al. 2007). These processes occur while the new forming vessels are simultaneously acquiring the capacity to regulate vascular tone and undergoing developmental changes in the contractile apparatus, the density of receptors and the signal transduction pathways leading to contraction/relaxation (Altimiras et al. 2009). This results in developmental changes in vascular reactivity. In this study, we analyzed the maturational differences in the reactivity of MAs isolated from chicken embryos and hatchlings. We found that MAs from 15-day chick embryos responded to $\mathrm{K}^{+}$-evoked depolarization and to a variety of agonists (NE,

\section{NH1d}
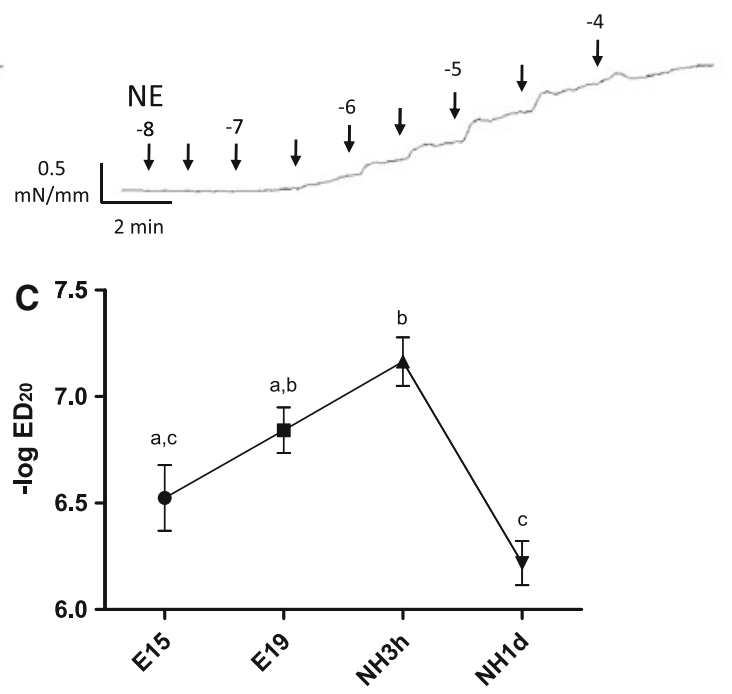

$(P<0.05)$. In a (representative tracings), numbers above the arrows indicate $\log \mathrm{M}[\mathrm{NE}]$ and arrows without numbers indicate half-log increments in concentration

ET-1, ACh, SNP, forskolin) indicating the presence at this stage of development of electro- and pharmaco-mechanical coupling as well as cGMP- and cAMP-mediated relaxation. In ovo development and transition to ex ovo life was accompanied by alterations in the response of the MAs, but a different developmental trajectory was observed for each reactivity pathway tested. Thus, the efficacy of $\mathrm{K}^{+}$to contract MAs underwent a linear developmental increase (E15 < E19 < NH3h $<$ NH1d), whereas the efficacy of NE and U46619 increased in ovo, but not ex ovo $(\mathrm{E} 15<\mathrm{E} 19=\mathrm{NH} 3 \mathrm{~h}=\mathrm{NH} 1 \mathrm{~d})$, and the efficacy of ET-1 reached a peak in the E19 chicken $(\mathrm{E} 15<\mathrm{E} 19>$ $\mathrm{NH} 3 \mathrm{~h}=\mathrm{NH} 1 \mathrm{~d})$. The relaxations elicited by ACh, SNP, and forskolin did not undergo dramatic developmental changes, suggesting that maturation of vasodilator mechanisms precedes that of vasoconstrictor mechanisms.

Response of mesenteric arteries to contractile stimuli

$\mathrm{KCl}$ has long been used as a tool to bypass $\mathrm{G}$ proteincoupled receptors and activate smooth muscle by a highly reproducible receptor-independent mechanism involving depolarization, activation of voltage-operated $\mathrm{Ca}^{2+}$ channels, increase in cytosolic-free $\mathrm{Ca}^{2+}, \mathrm{Ca}^{2+}$-dependent myosin light chain phosphorylation and contraction (Ratz et al. 2005). Although recent data indicate that $\mathrm{KCl}$ also can regulate the degree of $\mathrm{Ca}^{2+}$ sensitivity in smooth muscle, $\mathrm{KCl}$-induced contraction is often used to examine the smooth muscle contraction function and to standardize the receptor-mediated contraction (Ratz et al. 2005). In the present work, we observed that $\mathrm{KCl}$-evoked depolarization 
$\begin{array}{lll}\text { A } & \text { E19 }\end{array}$

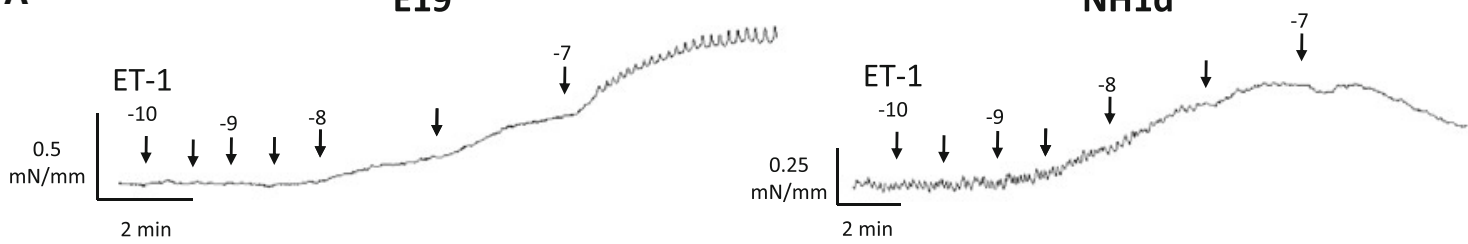

B

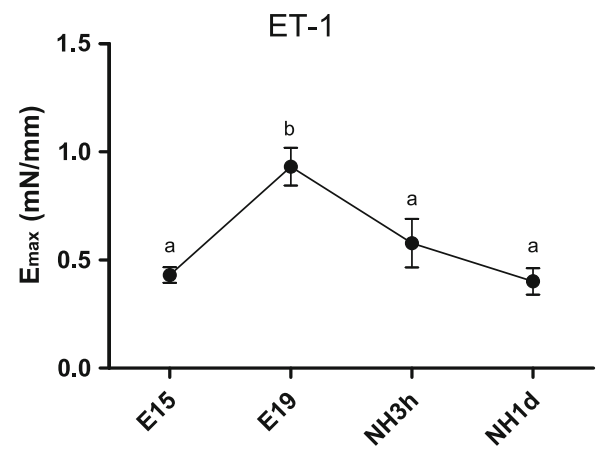

D

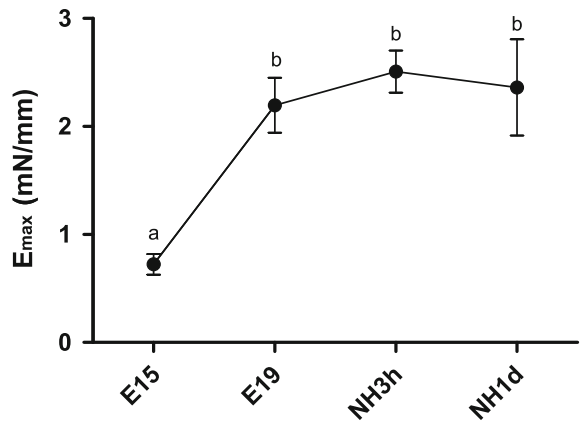

Fig. 3 Contractile effects of endothelin-1 (ET-1, a-c) and the TP receptor agonist U46619 (d, e) in mesenteric arteries from 15-day (E15) and 19-day (E19) chicken embryos and 3-h-old (NH3h) and 1-day-old (NH1d) newly hatched chicks. Values (mean \pm SEM)

induced a significant contraction in the MA of the 15-day embryos indicating the presence of a relatively mature contractile apparatus. Interestingly, the magnitude of $\mathrm{KCl}-$ induced contraction in MA increased two and half-fold between days 15 and 19, whereas in chicken embryo carotid and femoral arteries $\mathrm{KCl}-$ evoked contraction increased five- to sevenfold during the same incubation period (le Noble et al. 2000, Fig. 5). Sensitivity to $\mathrm{KCl}$ was unaltered over the period we examined. The developmental differences in $\mathrm{KCl}$-induced contraction could reflect an increase in vascular smooth muscle mass or dissimilarities in vascular smooth muscle phenotype. The expression of smooth muscle proteins and myosin heavy chain isoforms have been shown to be developmentally regulated and tissue dependent in mammals (Sakurai et al. 1996; Slomp
C

ET-1

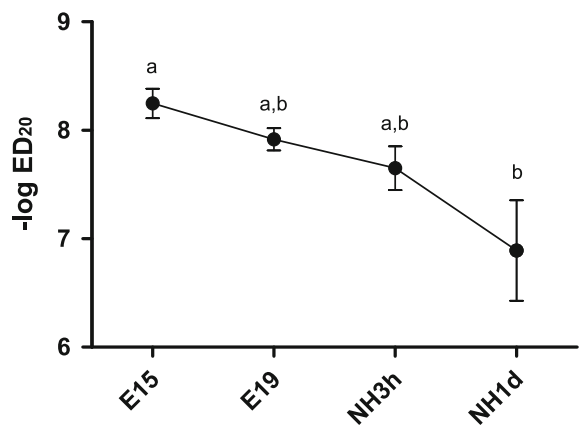

E

U46619

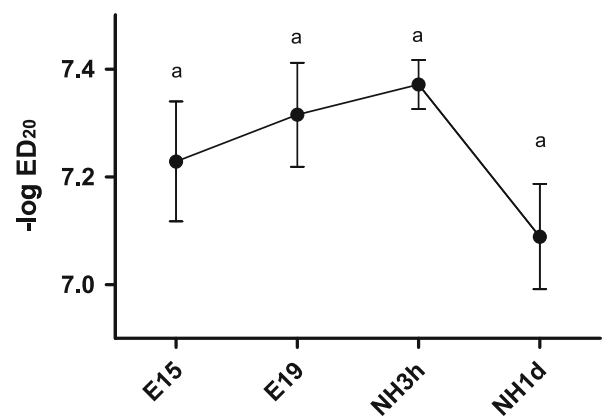

without a common letter are significantly different $(P<0.05)$. In a (representative tracings), numbers above the arrows indicate $\log \mathrm{M}$ [ET-1] and arrows without numbers indicate half-log increments in concentration

et al. 1997). From the different chicken embryo vessels that our group have studied-carotid, femoral, pulmonary, chorioallantoic (CA) arteries, and ductus arteriosus (DA) only the DA (Agren et al. 2007; Flinsenberg et al. 2010; Moonen et al. 2010b) and the CA arteries (Lindgren et al. 2010) showed an early "mature" contractile function at E15 comparable to the one observed in the MA (Fig. 5). This high degree of responsiveness of the E15 MA suggests the presence of an active control of mesenteric circulation at this stage of development.

Catecholamines play a key role in the prenatal cardiovascular response to stress and in several of the adaptations that characterize the transition from the pre- to the neonatal period (Mulder et al. 2000, 2001, 2002). In the mammalian fetus, the cardiovascular responses to acute hypoxia 
A

E19

NH1d

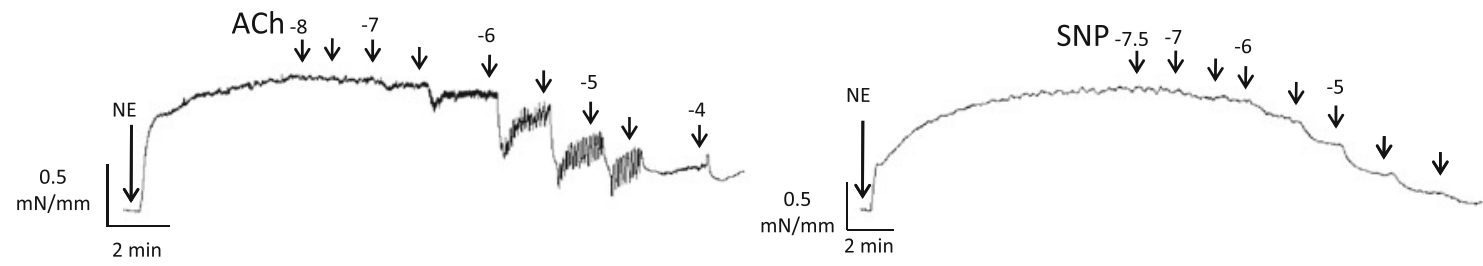

B

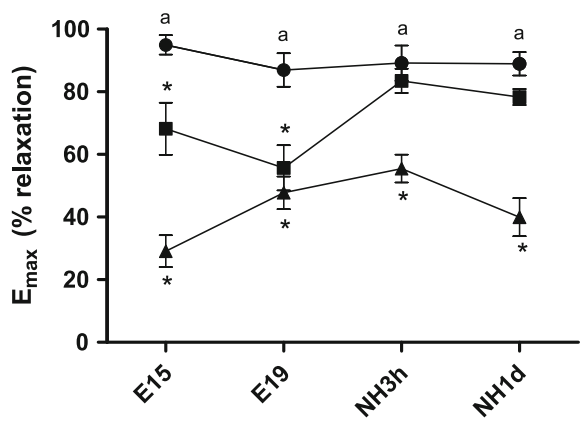

D

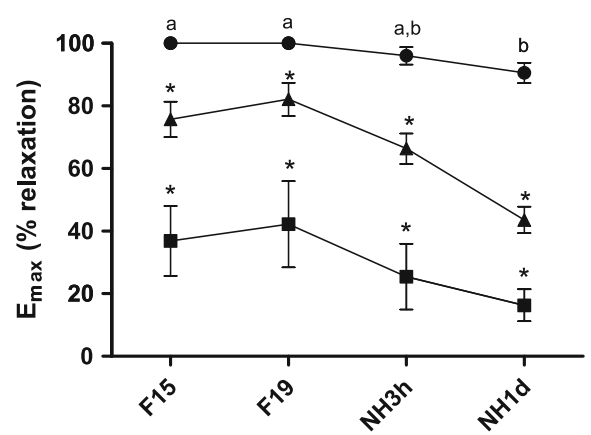

$\mathbf{F}$

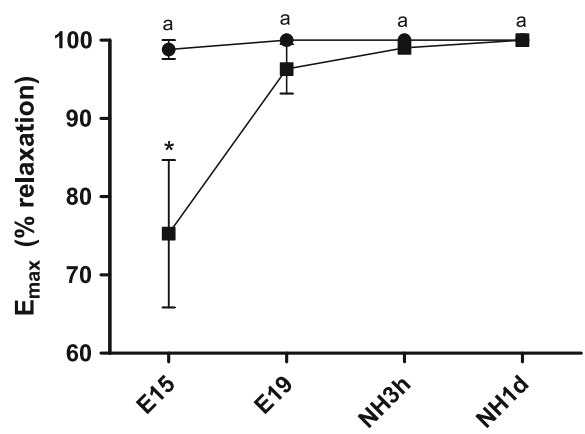

Fig. 4 Relaxant effects of acetylcholine (ACh, a left and $\mathbf{b}, \mathbf{c}$ ) sodium nitroprusside (SNP, a right and $\mathbf{d}, \mathbf{e}$ ) and forskolin $(\mathbf{f}, \mathbf{g})$ in mesenteric arteries from 15-day (E15) and 19-day (E19) chicken embryos and 3-h-old (NH3h) and 1-day-old (NH1d) newly hatched chicks. The vessels were contracted with $\mathrm{KCl}(62.5 \mathrm{mM})$ or norepinephrine $(10 \mu \mathrm{M})$. The effects of the NO synthase inhibitor L-NAME $(0.1 \mathrm{mM}, \mathbf{b})$ and the soluble guanylate cyclase ODQ $(10 \mu \mathrm{M}, \mathbf{d})$ on
C

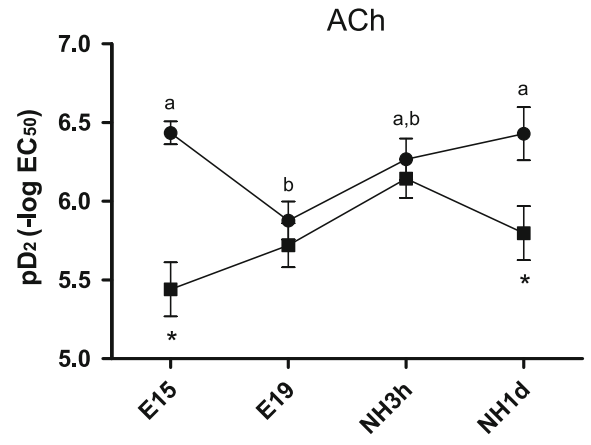

E

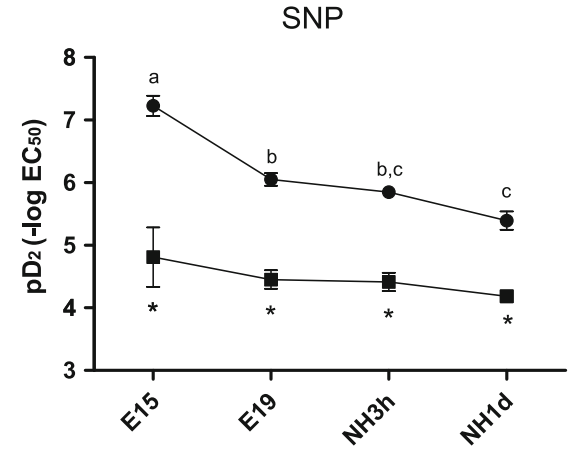

G

Forskolin

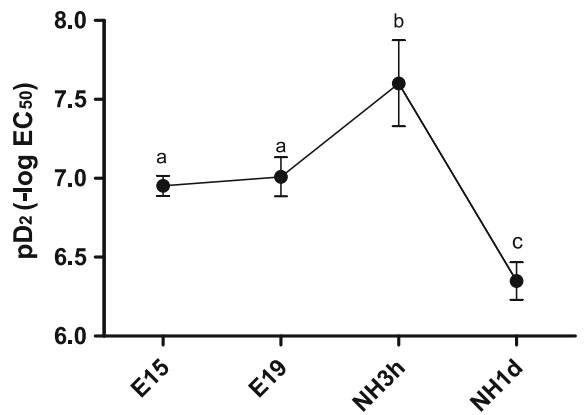

ACh- and SNP-evoked relaxation are also shown. Developmental changes: values (mean $\pm \mathrm{SEM}$ ) without a common letter are significantly different $(P<0.05)$. $* P<0.05$ versus NE-contracted (same age). In a (representative tracings), numbers above the arrows indicate $\log \mathrm{M}$ [drug] and arrows without numbers indicate half-log increments in concentration 


\section{mesenteric ductus art. chorioallantoic pulmonary femoral carotid}
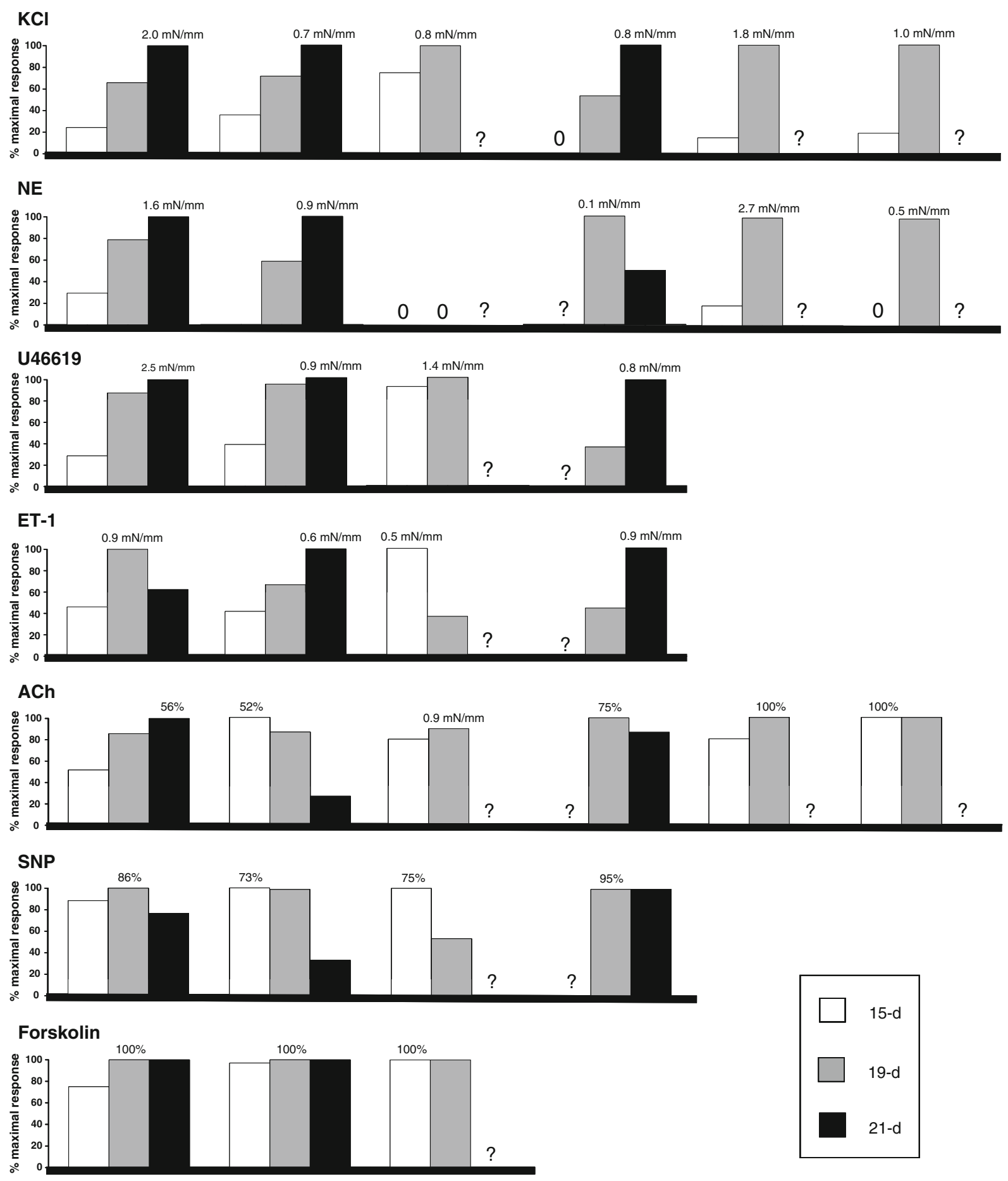

Fig. 5 Overview of the developmental changes in vascular reactivity of the chicken embryo. The figure has been constructed with data from the present work (mesenteric artery); Agren et al. 2007, 2008 and 2009 (ductus arteriosus); Lindgren et al. 2010 (chorioallantoic artery); Villamor et al. 2002 (pulmonary artery); and le Noble et al. 2000 (femoral and carotid arteries). The 21-day group is formed by newly hatched chicks (mesenteric arteries) or externally pipped embryos (rest of the vessels). The data are presented as percent of the maximal response observed among the three ages. This maximal response is indicated above the corresponding column (as $\mathrm{mN} / \mathrm{mm}$ for the contractions and as percent relaxation for the relaxations). The "?" symbol means unknown data and the "0" means no response. For the study of the relaxant responses, the vessels were pre-contracted with $\mathrm{KCl}$. Note that $\mathrm{ACh}$ did not evoke relaxation, but contraction in the chorioallantoic arteries. NE norepinephrine, U46619 9,11-dideoxy$11 \alpha, 9 \alpha$-epoxymethano-prostaglandin $\mathrm{F}_{2 \alpha}$ (TP receptor agonist), ET-1 endothelin-1, ACh acetylcholine, SNP sodium nitroprusside 
include a redistribution of the cardiac output away from the periphery towards high priority organs, such as the heart, brain, and adrenal gland (Llanos et al. 2003). Similarly, in the chicken embryo acute hypoxia caused a redistribution of the cardiac output in favor of heart, brain and CA membrane at the expense of intestine, yolk sac, liver, and carcass (Mulder et al. 1998). A component of the this protective redistribution is mediated by increased release of catecholamines (Mulder et al. 2000, 2001, 2002), whose effects would be modulated by the different responsiveness of the vascular beds. Accordingly, we show herein that NE induced a significant contraction in the E15 MA and, in a previous study, Rouwet et al. (2000) demonstrated that NEinduced vasoconstriction was already present in secondorder MAs of 13-day chicken embryos. They also observed a developmental increase in the MA responsiveness to NE similar to the described in the present study. Interestingly, the development of adrenergic contraction in the chicken carotid artery (le Noble et al. 2000) and DA (Agren et al. 2007) is slower than the observed in the MA (Fig. 5). Moreover, the chicken CA arteries did not show adrenergic contraction at any stage of development (Lindgren et al. 2010). Taken all together, these results show a correlation between the distribution of cardiac output during hypoxia (i.e. increased to the brain and the CA membrane and decreased to the intestine) and the local vascular responses to adrenergic stimulation.

ET-1 is a vasoactive and mitogenic polypeptide produced mainly by the vascular endothelium. Its binding to $\mathrm{ET}_{\mathrm{A}}$ and $\mathrm{ET}_{\mathrm{B}}$ receptors on vascular smooth muscle induces contraction, whereas its binding to endothelial $\mathrm{ET}_{\mathrm{B}}$ receptors causes vasodilatation (Granger 2003; Reber et al. 2002). ET-1 is constitutively produced, but its production can also be stimulated by a wide range of stimuli, including decreased flow, hypoxia, and various inflammatory cytokines. In some mammalian species, ET-1 is considered as the primary vasoconstrictor stimulus in the perinatal intestinal circulation (Nankervis et al. 2008; Nankervis and Nowicki 2000; Reber et al. 2002). In the present work, we show the responsiveness of embryonic and newly hatched chicken MA to ET-1. Previously we demonstrated ET1-induced contraction in chicken embryo femoral, pulmonary, and CA arteries as well as in the DA (Fig. 5). Interestingly, ET-1-induced contraction reached a peak in the E19 and decreased in the NH chicken. Moreover, high concentrations of ET-1-induced relaxation in the MA from $\mathrm{NH}$ chickens. Although, we have not characterized the nature of the response to ET-1, our results suggest the presence of $\mathrm{ET}_{\mathrm{A}}$-mediated contraction in the embryonic arteries and the combination of $\mathrm{ET}_{\mathrm{A}}$-mediated contraction and $\mathrm{ET}_{\mathrm{B}}$-mediated relaxation in the $\mathrm{MA}$ from the $\mathrm{NH}$ chickens. Endothelial $\mathrm{ET}_{\mathrm{B}}$ receptors are abundantly present in 1- to 3-day-old swine intestine and their activation leads to a modest NO-dependent vasodilatation. However, the force of $\mathrm{ET}_{\mathrm{A}}$-induced vasoconstriction exceeds that of $\mathrm{ET}_{\mathrm{B}}$-generated vasodilatation, such that the net effect of the constitutive production of ET-1 in the swine neonatal intestine resistance vessels is vasoconstriction (Nankervis et al. 2008; Nankervis and Nowicki 2000; Reber et al. 2002). The present findings in the chicken MA warrant further investigation into the constitutive production of ET-1 and the developmental changes in ET receptor density.

The TP receptor agonist U46619-evoked contraction of chicken embryo mesenteric (present work), pulmonary (Villamor et al. 2002), femoral (Zoer et al. 2010a, b), CA (Lindgren et al. 2010) arteries and DA (Agren et al. 2007; Schuurman and Villamor 2010) (Fig. 5). Sensitivity of the MA to U46619 was unaltered over the period we examined, but the magnitude of U46619-induced contraction increased threefold between E15 and E19. Accordingly, U46619-evoked contraction of fetal lamb MAs increased with gestational age (Wolfs et al. 2009). In the first hours of ex ovo life, the responsiveness of chicken MA to U46619 remained unchanged and our study was not extended beyond that time point. However, a postnatal decrease in MA responsiveness to U46619 and other TP receptor agonists (such as isoprostanes) has been characterized in swine (Gonzalez-Luis et al. 2005), suggesting that TP receptor agonists may play a role in the postnatal reduction of mesenteric vascular resistance.

\section{Relaxant responses}

ACh has been widely used in numerous vascular beds to stimulate endothelium-dependent relaxation (GonzálezLuis et al. 2007; Ignarro 2002). Several endotheliumderived relaxing factors have been found, including NO, prostaglandins, carbon monoxide and a yet unidentified factor called endothelium-derived hyperpolarizing factor (EDHF, Baragatti et al. 2007; Busse et al. 2002). The contribution of each of these factors to endotheliumdependent relaxation varies across vascular beds and also with the physiological or pharmacological stimuli used to stimulate the endothelium (Busse et al. 2002). In the chicken embryo, ACh induced an endothelium-dependent and, at least partially, NO-mediated relaxation of the DA (Agren et al. 2007; Schuurman and Villamor 2010), the pulmonary (Villamor et al. 2002), the femoral (Villamor et al. 2002), and the carotid arteries (le Noble et al. 2000) (Fig. 5). In the present work, we show that ACh evoked endothelium-dependent relaxation in MA from embryonic and $\mathrm{NH}$ chickens. Rouwet et al. showed that ACh-induced vasodilatation was already present in E13 MAs. Herein, we observed that the efficacy and potency of ACh in relaxing MAs did not change with development. However, the NO 
synthase inhibitor L-NAME decreased the efficacy $\left(E_{\max }\right)$ of ACh in embryonic, but not in $\mathrm{NH}$ arteries and decreased the potency $\left(p D_{2}\right)$ of ACh only in the E15 and the $1 \mathrm{dNH}$ vessels, suggesting developmental differences in the underlying mechanism(s). Thus, our results suggest a more relevant role of NO in the endothelium-dependent actions of $\mathrm{ACh}$ in the MAs from the less mature animals.

The identity of EDHF remains uncertain, but it is accepted that its action involves an increase in $\mathrm{K}^{+}$conductance and can, therefore, be inhibited by abolishing the electrochemical gradient for $\mathrm{K}^{+}$ions. This was conducted in these studies using a solution containing $62.5 \mathrm{mM} \mathrm{K}^{+}$to induce tone. Under these experimental conditions, it was observed a significant impairment of ACh-induced relaxation. This impairment was similar in the four age groups and may suggest a relevant role for EDHF in perinatal chicken MAs. However, we observed that SNP was also less efficacious in $\mathrm{KCl}$ - than in NE-contracted arteries indicating that sGC-dependent relaxation is also affected by depolarization in this preparation. Interestingly, the relaxant efficacy of the adenylate cyclase stimulator forskolin was impaired by high $\mathrm{K}^{+}$depolarizing solution only in the youngest vessels. Again, the maturational changes in MA reactivity appear to affect not only the potency/efficacy of the vasoactive agonists, but also alterations in the underlying pathways.

\section{Significance and perspectives}

The control of intestinal vascular resistance during the perinatal period is a complex process that integrates the intestinal circulation into cardiovascular reflexes which preserve systemic homeostasis, often at the expense of the local intestinal circulation (Duckles and Banner 1984; Nowicki 1990). As reviewed by Nankervis et al. (2008), the mammalian intestinal vascular tone is maintained by a dynamic balance between constrictor (ET-1) and dilator (NO) stimuli. In the newborn, under steady state conditions, the balance favors vasodilatation generating an increased rate of blood flow to the newborn intestine to meet the metabolic demands of early postnatal life. Our data suggest the presence of similar regulatory mechanisms in the chicken mesenteric circulation. Understanding the basic mechanisms of either normal or altered functional and structural development of the mesenteric vessels, as well as inter-species differences in mesenteric circulation, may provide insights into human and animal intestinal disease.

Open Access This article is distributed under the terms of the Creative Commons Attribution Noncommercial License which permits any noncommercial use, distribution, and reproduction in any medium, provided the original author(s) and source are credited.

\section{References}

Agren P, Cogolludo AL, Kessels CG, Perez-Vizcaino F, De Mey JG, Blanco CE, Villamor E (2007) Ontogeny of chicken ductus arteriosus response to oxygen and vasoconstrictors. Am J Physiol Regul Integr Comp Physiol 292:R485-R496

Agren P, van der Sterren S, Cogolludo AL, Frazziano G, de Mey JG, Blanco CE, Villamor E (2008) Developmental changes in endothelium-dependent relaxation of the chicken ductus arteriosus. J Physiol Pharmacol 59:55-76

Agren P, van der Sterren S, Cogolludo AL, Blanco CE, Villamor E (2009) Developmental changes in the effects of prostaglandin E2 in the chicken ductus arteriosus. J Comp Physiol B 179:133-143

Altimiras J, Crossley DA 2nd (2000) Control of blood pressure mediated by baroreflex changes of heart rate in the chicken embryo (Gallus gallus). Am J Physiol Regul Integr Comp Physiol 278:R980-R986

Altimiras J, Crossley DA, Villamor E (2009) Prenatal development of cardiovascular regulation in avian species. In: Glass ML, Wood SC (eds) Cardio-respiratory control in vertebrates comparative and evolutionary aspects. Springer, Berlin, pp 397-427

Baragatti B, Brizzi F, Barogi S, Laubach VE, Sodini D, Shesely EG, Regan RF, Coceani F (2007) Interactions between NO, CO and an endothelium-derived hyperpolarizing factor (EDHF) in maintaining patency of the ductus arteriosus in the mouse. $\mathrm{Br} \mathrm{J}$ Pharmacol 151:54-62

Biviano AB, Martinez del Rio C, Phillips DL (1993) Ontogenesis of intestine morphology and intestinal disaccharidases in chickens (Gallus gallus) fed contrasting purified diets. J Comp Physiol B 163:508-518

Busse R, Edwards G, Feletou M, Fleming I, Vanhoutte PM, Weston AH (2002) EDHF: bringing the concepts together. Trends Pharmacol Sci 23:374-380

Duckles SP, Banner W Jr (1984) Changes in vascular smooth muscle reactivity during development. Ann Rev Pharmaco Toxicol 24:65-83

Edelstone DI, Holzman IR (1982) Fetal intestinal oxygen consumption at various levels of oxygenation. Am J Physiol 242:H50 H54

Flinsenberg TW, Van der Sterren S, van Cleef AN, Schuurman MJ, Agren P, Villamor E (2010) Effects of gender and estrogen on chicken ductus arteriosus reactivity. Am J Physiol Regul Integr Comp Physiol 298:R1217-R1224

Gluais P, Lonchampt M, Morrow JD, Vanhoutte PM, Feletou M (2005) Acetylcholine-induced endothelium-dependent contractions in the SHR aorta: the Janus face of prostacyclin. Br J Pharmacol 146:834-845

Gonzalez-Luis G, Perez-Vizcaino F, Garcia-Munoz F, de Mey JG, Blanco CE, Villamor E (2005) Age-related differences in vasoconstrictor responses to isoprostanes in piglet pulmonary and mesenteric vascular smooth muscle. Pediatr Res 57:845-852

González-Luis G, Fletcher AJW, Moreno L, Perez-Vizcaino F, Blanco CE, Villamor E (2007) Nitric oxide-mediated nonadrenergic noncholinergic relaxation of piglet pulmonary arteries decreases with postnatal age. J Physiol Pharmacol 58:45-56

Granger JP (2003) Endothelin. Am J Physiol Regul Integr Comp Physiol 285:R298-R301

Heymann MA, Iwamoto HS, Rudolph AM (1981) Factors affecting changes in the neonatal systemic circulation. Annu Rev Physiol 43:371-383

Ignarro LJ (2002) Nitric oxide as a unique signaling molecule in the vascular system: a historical overview. J Physiol Pharmacol 53:503-514

le Noble FA, Ruijtenbeek K, Gommers S, de Mey JG, Blanco CE (2000) Contractile and relaxing reactivity in carotid and femoral 
arteries of chicken embryos. Am J Physiol Heart Circ Physiol 278:H1261-H1268

Levinsohn EM, Packard DS Jr, West EM, Hootnick DR (1984) Arterial anatomy of chicken embryo and hatchling. Am J Anat 169:377-405

Lin PW, Nasr TR, Stoll BJ (2008) Necrotizing enterocolitis: recent scientific advances in pathophysiology and prevention. Semin Perinatol 32:70-82

Lindgren I, Zoer B, Altimiras J, Villamor E (2010) Reactivity of chicken chorioallantoic arteries, avian homologue of human fetoplacental arteries. J Physiol Pharmacol 61:619-628

Llanos AJ, Riquelme RA, Sanhueza EM, Hanson MA, Blanco CE, Parer JT, Herrera EA, Pulgar VM, Reyes RV, Cabello G, Giussani DA (2003) The fetal llama versus the fetal sheep: different strategies to withstand hypoxia. High Alt Med Biol 4:193-202

Moonen RM, Paulussen AD, Souren NY, Kessels AG, RubioGozalbo ME, Villamor E (2007) Carbamoyl phosphate synthetase polymorphisms as a risk factor for necrotizing enterocolitis. Pediatr Res 62:188-190

Moonen RM, Reyes I, Cavallaro G, Gonzalez-Luis G, Bakker JA, Villamor E (2010a) The T1405N carbamoyl phosphate synthetase polymorphism does not affect plasma arginine concentrations in preterm infants. PloS one 5:e10792

Moonen RMJ, Agren P, Cogolludo AL, Perez-Vizcaino F, Villamor E (2010b) Response of chicken ductus arteriosus to hypercarbic and normocarbic acidosis. Neonatology 98:47-56

Mulder AL, van Golde JC, Prinzen FW, Blanco CE (1998) Cardiac output distribution in response to hypoxia in the chick embryo in the second half of the incubation time. J Physiol 508:281-287

Mulder AL, Golde JM, Goor AA, Giussani DA, Blanco CE (2000) Developmental changes in plasma catecholamine concentrations during normoxia and acute hypoxia in the chick embryo. J Physiol 527(Pt 3):593-599

Mulder AL, van Goor CA, Giussani DA, Blanco CE (2001) Alphaadrenergic contribution to the cardiovascular response to acute hypoxemia in the chick embryo. Am J Physiol Regul Integr Comp Physiol 281:R2004-R2010

Mulder AL, Miedema A, De Mey JG, Giussani DA, Blanco CE (2002) Sympathetic control of the cardiovascular response to acute hypoxemia in the chick embryo. Am J Physiol Regul Integr Comp Physiol 282:R1156-R1163

Nankervis CA, Nowicki PT (2000) Role of endothelin-1 in regulation of the postnatal intestinal circulation. Am J Physiol Gastrointest Liver Physiol 278:G367-G375

Nankervis CA, Reber KM, Nowicki PT (2001) Age-dependent changes in the postnatal intestinal microcirculation. Microcirculation 8:377-387

Nankervis CA, Giannone PJ, Reber KM (2008) The neonatal intestinal vasculature: contributing factors to necrotizing enterocolitis. Semin Perinatol 32:83-91

Nowicki P (1990) Intestinal ischemia and necrotizing enterocolitis. J Pediatr 117:S14-S19

Noy Y, Sklan D (1998) Yolk utilisation in the newly hatched poult. Br Poult Sci 39:446-451

Noy Y, Sklan D (2001) Yolk and exogenous feed utilization in the posthatch chick. Poult Sci 80:1490-1495

Owens GK, Kumar MS, Wamhoff BR (2004) Molecular regulation of vascular smooth muscle cell differentiation in development and disease. Physiol Rev 84:767-801

Powell KA, Deans EA, Speake BK (2004) Fatty acid esterification in the yolk sac membrane of the avian embryo. J Comp Physiol B 174:163-168
Ratz PH, Berg KM, Urban NH, Miner AS (2005) Regulation of smooth muscle calcium sensitivity: $\mathrm{KCl}$ as a calcium-sensitizing stimulus. Am J Physiol Cell Physiol 288:C769-C783

Reber KM, Nankervis CA, Nowicki PT (2002) Newborn intestinal circulation. Physiology and pathophysiology. Clin Perinatol 29:23-39

Rouwet EV, De Mey JG, Slaaf DW, Heineman E, Ramsay G, Le Noble FA (2000) Development of vasomotor responses in fetal mesenteric arteries. Am J Physiol Heart Circ Physiol 279: H1097-H1105

Ruijtenbeek K, De Mey JG, Blanco CE (2002) The chicken embryo in developmental physiology of the cardiovascular system: a traditional model with new possibilities. Am J Physiol Regul Integr Comp Physiol 283:R549-R550

Rzucidlo EM, Martin KA, Powell RJ (2007) Regulation of vascular smooth muscle cell differentiation. J Vasc Surg 45(Suppl A):A25-A32

Sakurai H, Matsuoka R, Furutani Y, Imamura S, Takao A, Momma K (1996) Expression of four myosin heavy chain genes in developing blood vessels and other smooth muscle organs in rabbits. Eur J Cell Biol 69:166-172

Schuurman MJ, Villamor E (2010) Endothelium-dependent contraction induced by acetylcholine in the chicken ductus arteriosus involves cyclooxygenase- 1 activation and TP receptor stimulation. Comp Biochem Physiol A Mol Integr Physiol 157:28-34

Sklan D (2003) Fat and carbohydrate use in posthatch chicks. Poult Sci $82: 117-122$

Slomp J, Gittenberger-de Groot AC, Glukhova MA, Conny van Munsteren J, Kockx MM, Schwartz SM, Koteliansky VE (1997) Differentiation, dedifferentiation, and apoptosis of smooth muscle cells during the development of the human ductus arteriosus. Arterioscler Thromb Vasc Biol 17:1003-1009

Speake BK, Murray AM, Noble RC (1998) Transport and transformations of yolk lipids during development of the avian embryo. Prog Lipid Res 37:1-32

Sutendra G, Michelakis ED (2007) The chicken embryo as a model for ductus arteriosus developmental biology: cracking into new territory. Am J Physiol Regul Integr Comp Physiol 292:R481R484

Uni Z, Tako E, Gal-Garber O, Sklan D (2003) Morphological, molecular, and functional changes in the chicken small intestine of the late-term embryo. Poult Sci 82:1747-1754

Villamor E, Ruijtenbeek K, Pulgar V, De Mey JG, Blanco CE (2002) Vascular reactivity in intrapulmonary arteries of chicken embryos during transition to ex ovo life. Am J Physiol Regul Integr Comp Physiol 282:R917-R927

Wolfs TG, Buurman WA, Zoer B, Moonen RM, Derikx JP, Thuijls G, Villamor E, Gantert M, Garnier Y, Zimmermann LJ, Kramer BW (2009) Endotoxin induced chorioamnionitis prevents intestinal development during gestation in fetal sheep. PloS one 4:e5837

Zoer B, Kessels L, Vereijken A, De Mey JG, Bruggeman V, Decuypere E, Blanco CE, Villamor E (2009) Effects of prenatal hypoxia on pulmonary vascular reactivity in chickens prone to pulmonary hypertension. J Physiol Pharmacol 60:119-130

Zoer B, Blanco CE, Villamor E (2010a) Role of Rho-kinase in mediating contraction of chicken embryo femoral arteries. J Comp Physiol B 180:427-435

Zoer B, Cogolludo AL, Perez-Vizcaino F, De Mey JG, Blanco CE, Villamor E (2010b) Hypoxia sensing in the fetal chicken femoral artery is mediated by the mitochondrial electron transport chain. Am J Physiol Regul Integr Comp Physiol 298:R1026-R1034 